\title{
Characteristics and risk factors for SARS-CoV-2 in children tested in the early phase of the pandemic: a cross-sectional study, Italy, 23 February to 24 May 2020
}

Marzia Lazzerini ${ }^{1}$, Idanna Sforzi ${ }^{2}$, Sandra Trapani ${ }^{3}$, Paolo Biban ${ }^{4}$, Davide Silvagni ${ }^{4}$, Giovanna Villa ${ }^{5}$, Jessica Tibaldi ${ }^{5}$, Luca Bertacca $^{6}$, Enrico Felici ${ }^{7}$, Giuseppina Perricone ${ }^{7}$, Roberta Parrino ${ }^{8}$, Claudia Gioè ${ }^{\text {, Sara Lega }}{ }^{1}$, Mariasole Conte ${ }^{1}$, Federico Marchetti $^{10}$, Annamaria Magista ${ }^{11}$, Paola Berlese ${ }^{12}$, Stefano Marteloss ${ }^{12}$, Francesca Vaienti ${ }^{13}$, Enrico Valletta ${ }^{13}$, Margherita Mauro $^{14}$, Roberto Dall'Amico ${ }^{14}$, Silvia Fasoli ${ }^{15}$, Antonio Gatto ${ }^{16}$, Antonio Chiaretti ${ }^{16}$, Danica Dragovic ${ }^{17}$, Paola Pascolo ${ }^{17}$, Chiara Pilotto $^{18}$, Ilaria Liguoro ${ }^{18}$, Elisabetta Miorin ${ }^{19}$, Francesca Saretta ${ }^{19}$, Gian Luca Trobia ${ }^{20}$, Antonella Di Stefano ${ }^{20}$, Azzurra Orlandi ${ }^{21}$ , Fabio Cardinale ${ }^{21}$, Riccardo Lubrano ${ }^{22}$, Alessia Testa ${ }^{22}$, Marco Binotti ${ }^{23}$, Valentina Moressa ${ }^{1}$, Egidio Barbi ${ }^{1,24}$, Benedetta

Armocida $^{1}$, Ilaria Mariani ${ }^{1}$, on behalf of COVID-19 Italian Pediatric Study Network ${ }^{25}$

1. Institute for Maternal and Child Health - IRCCS "Burlo Garofolo", Trieste, Italy

2. Department of Pediatric Emergency Medicine and Trauma Center, Meyer Children's University Hospital, Florence, Italy

3. Department of Health Sciences and Meyer Children's University Hospital, Florence, Italy

4. Department of Neonatal and Paediatric Critical Care, Verona University Hospital, Verona Italy

5. Pediatric Emergency Unit, IRCCS Gaslini Children's Hospital, Genoa, Italy

6. Pediatric Emergency Unit and Department of Pediatric and Neonatology, Misericordia Hospital, Grosseto, Italy

7. Pediatric and Pediatric Emergency Unit, The Children Hospital, AO SS Antonio e Biagio e Cesare Arrigo, Alessandria, Italy

8. Pediatria d’Urgenza e Pronto Soccorso P.O.G. Di Cristina, Palermo, Italy

9. Pediatric Infectious diseases, P.O.G. Di Cristina, Palermo, Italy

10. Department of Pediatrics, Ravenna Hospital, Ravenna, Italy

11. Department of Pediatrics, Community Pediatrics, Ravenna, Italy

12. Department of Pediatrics, Treviso Hospital, Treviso, Italy

13. Department of Pediatrics, G.B. Morgagni-L. Pierantoni Hospital, Forlì, Italy

14. Department of Pediatrics and Neonatology, Santa Maria degli Angeli Hospital, Pordenone, Italy

15. Paediatric Unit, Carlo Poma Hospital, Mantua, Italy

16. Department of Woman and Child Health and Public Health, Fondazione Policlinico Universitario A. Gemelli IRCCS, Rome, Italy

17. Department of Pediatrics, San Polo Hospital, ASUGI, Monfalcone (GO), Italy

18. Division of Paediatrics, Department of Medicine DAME, Academic Hospital Santa Maria della Misericordia, University of Udine, Udine, Italy

19. Department of Pediatrics, Latisana-Palmanova, ASUFC, Udine, Italy

20. Pediatric and Pediatric Emergency Room Unit Cannizzaro Emergency Hospital, Catania, Italy

21. Giovanni XXIII Pediatric Hospital, Department of Pediatrics, University of Bari, Bari, Italy

22. Department of Pediatrics Sapienza University of Rome, Santa Maria Goretti Hospital, Latina, Italy

23. Neonatal and Pediatric Intensive Care Unit, Maggiore della Carità University Hospital, Novara, Italy

24. University of Trieste, Trieste, Italy

25. Members of the COVID-19 Italian Pediatric Study Network are acknowledged at the end of the article

Correspondence: Marzia Lazzerini (marzia.lazzerini@burlo.trieste.it)

Citation style for this article:

Lazzerini Marzia, Sforzi Idanna, Trapani Sandra, Biban Paolo, Silvagni Davide, Villa Giovanna, Tibaldi Jessica, Bertacca Luca, Felici Enrico, Perricone Giuseppina, Parrino Roberta, Gioè Claudia, Lega Sara, Conte Mariasole, Marchetti Federico, Magista Annamaria, Berlese Paola, Martelossi Stefano, Vaienti Francesca, Valletta Enrico, Mauro Margherita, Dall'Amico Roberto, Fasoli Silvia, Gatto Antonio, Chiaretti Antonio, Dragovic Danica, Pascolo Paola, Pilotto Chiara, Liguoro Ilaria, Miorin Elisabetta, Saretta Francesca, Trobia Gian Luca, Di Stefano Antonella, Orlandi Azzurra, Cardinale Fabio, Lubrano Riccardo, Testa Alessia, Binotti Marco, Moressa Valentina, Barbi Egidio, Armocida Benedetta, Mariani Ilaria, on behalf of COVID-19 Italian Pediatric Study Network. Characteristics and risk factors for SARS-CoV-2 in children tested in the early phase of the pandemic: a cross-sectional study, Italy, 23 February to 24 May 2020. Euro Surveill. 2021;26(14):pii=2001248. https:// doi.org/10.2807/1560-7917.ES.2021.26.14.2001248

Background: Very few studies describe factors associated with COVID-19 diagnosis in children. Aim: We here describe characteristics and risk factors for COVID-19 diagnosis in children tested in 20 paediatric centres across Italy. Methods: We included cases aged 0-18 years tested between 23 February and 24 May 2020. Our primary analysis focused on children tested because of symptoms/signs suggestive of COVID-19.

Results: Among 2,494 children tested, 2,148 (86.1\%) had symptoms suggestive of COVID-19. Clinical presentation of confirmed COVID-19 cases included besides fever $(82.4 \%)$ and respiratory signs or symptoms $(60.4 \%)$ also gastrointestinal $(18.2 \%)$, neurological (18.9\%), cutaneous (3.8\%) and other unspecific influenza-like presentations (17.8\%). In multivariate analysis, factors significantly associated with SARSCoV-2 positivity were: exposure history (adjusted odds ratio (AOR): $39.83 ; 95 \%$ confidence interval (Cl): 17.52-90.55; $\mathrm{p}<0.0001$ ), cardiac disease (AOR: 3.10; $95 \%$ Cl: 1.19-5.02; $p<0.0001$ ), fever (AOR: 3.05\%; $95 \% \mathrm{Cl}: 1.67-5.58 ; \mathrm{p}=0.0003)$ and anosmia/ ageusia (AOR: $4.08 ; 95 \% \mathrm{Cl}: 1.69-9.84 ; \mathrm{p}=0.002$ ). Among 190 (7.6\%) children positive for SARS-CoV-2, only four (2.1\%) required respiratory support and two (1.1\%) were admitted to intensive care; all recovered. Conclusion: Recommendations for SARS-CoV-2 testing in children should consider the evidence of broader clinical features. Exposure history, fever and anosmia/ ageusia are strong risk factors in children for positive SARS-CoV-2 testing, while other symptoms did not 
help discriminate positive from negative individuals. This study confirms that COVID-19 was a mild disease in the general paediatric population in Italy. Further studies are needed to understand risk, clinical spectrum and outcomes of COVID-19 in children with preexisting conditions.

\section{Introduction}

The pandemic of severe acute respiratory syndrome coronavirus 2 (SARS-CoV-2) affected Italy as first country in Europe [1]. The Italian government declared a state of emergency on 31 January 2020 [2] and by 24 May 2020, a total of 229,858 cases of COVID-19 had been diagnosed across the country [3].

From the very beginning of the pandemic, data suggested that children are less affected than adults by COVID-19 [4-10]. However, timely diagnosis of SARSCoV-2 infection is not only important for the single individual, it is crucial to prevent the spread of the pandemic. A better understanding of the predictors of a positive SARS-CoV-2 test results may facilitate timely case finding and contact tracing and thus contribute to control the pandemic. It may also improve organisation of care in settings where diagnostic facilities are available but still require a considerable processing time, where diagnostic facilities are lacking and where diagnosis, in the absence of other tools, may need to be based on clinical characteristics alone.

Several systematic reviews have synthetised the clinical features and outcomes of paediatric cases with a confirmed SARS-CoV-2 infection [11-17] but as yet, few studies have explored the risk factors associated with a positive SARS-CoV-2-positive diagnostic swab test. It is currently not known whether factors indicating increased risk of SARS-CoV-2 infection in adults [1821], such as exposure history, obesity, lymphocytopenia or ground glass opacity at lung X-ray [19], apply to children. Previous studies in children [22-24] have generally had a small sample size and did not assess predictors of COVID-19 among symptomatic children. This study aimed to describe the characteristics of paediatric patients tested for SARS-CoV-2 during the early phase of the pandemic in 20 centres across Italy, and explore factors associated with a positive SARS-CoV-2positive swab test.

\section{Methods}

\section{Study design and participants}

This cross-sectional study is reported according to Strengthening the Reporting of Observational studies in Epidemiology (STROBE) guidelines [25]. Data were collected through a collaborative research network coordinated by the World Health Organization (WHO) Collaborating Centre for Maternal and Child Health at the Institute for Maternal and Child Health IRCCS Burlo Garofolo, Trieste, Italy. Children aged 0-18 years tested for SARS-CoV-2 in the period between 23 February and
24 May 2020 in any of the 20 paediatric centres participating in the network were included in the study.

National recommendations on SARS-CoV-2 testing did not change during the study period, and indicated testing for: (i) contacts of COVID-19-positive cases, (ii) cases of severe acute respiratory distress syndrome and (iii) cases with fever, cough or difficulty breathing and absence of another aetiology that could fully explain the clinical presentation [26]. In addition, based on the local epidemiology and on emerging evidence on COVID-19 [27-29], some facilities implemented during the study period local policies of testing all hospitalised children and/or children with gastrointestinal or cutaneous symptoms such as vasculitis.

SARS-CoV-2 infection was diagnosed, in line with national recommendations, using nasal or nasopharyngeal swab specimens collected by trained personnel and tested for SARS-CoV-2 nucleic acid in regional referral laboratories using WHO-recommended realtime RT-PCR assays.

\section{Data collection and management}

Data were collected with a standardised, field-tested online anonymous form, previously used for another study [12] and further optimised and adapted for the purpose of this study. The form collected variables to classify children in the following predefined categories: (i) children tested because of symptoms suggestive of COVID-19, (ii) asymptomatic children tested because of contact with a SARS-CoV-2-positive case and (iii) hospitalised children tested as part of a hospital screening programme. It included information on sociodemographic and clinical characteristics, diagnostic examinations, type of treatments, and outcomes. Both closed and open questions were used. Data were obtained from official medical records and entered in the form by clinical staff in charge of case management in each facility. Information for health workers on how to complete the form was embedded in the form itself. Data collection forms where checked in real time for internal consistency or missing data by trained personnel. Additional cross-checking and data cleaning were conducted before data analysis by two expert biostatisticians (authors IM and BA).

\section{Study variables}

We included in this study sociodemographic and clinical characteristics, diagnostic examinations, type of treatments, and outcomes variables. For children tested because of symptoms suggestive of COVID-19, disease severity was classified using predefined objective criteria adapted from a previously published classification [12] (Supplementary Table S1). Tachypnoea and tachycardia where defined as detailed in Supplementary Table S2. The outcome variable for multivariate analysis was testing positive for SARS-CoV-2. 
Study flow diagram, paediatric SARS-CoV-2, Italy, 23 February-24 May $2020(n=2,494)$

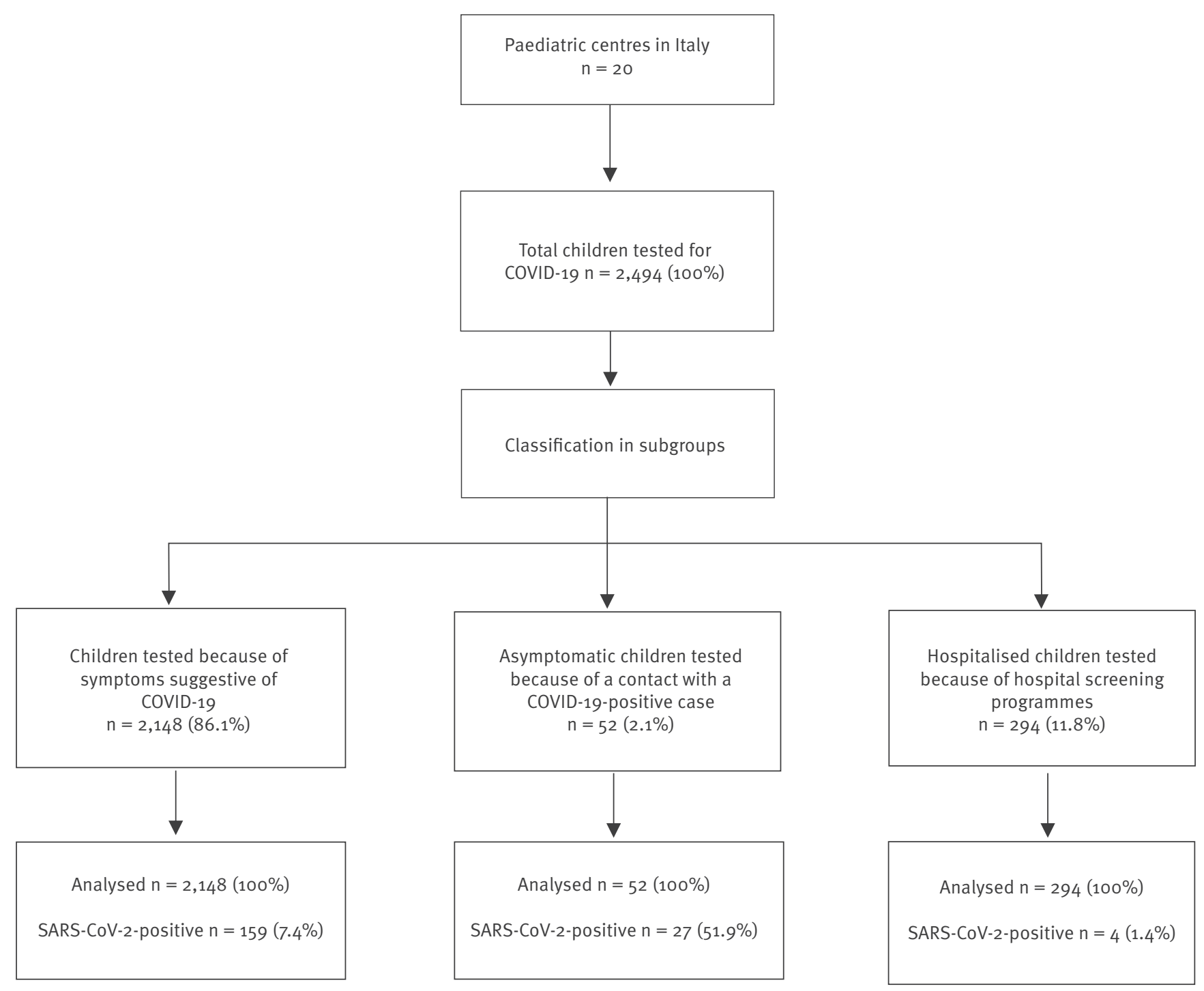

\section{Statistical analysis}

Categorical variables were reported as absolute numbers and percentages. Continuous variables were expressed as means and standard deviations (SD) or as median and interquartile ranges (IQR), if not normally distributed. We tested for associations between individual covariates and the outcome of a positive SARSCoV-2 swab using chi-square test or Fisher's exact test, as appropriate. Variables with a significant univariate relationship with the outcome, available in the whole sample, unless collinear, were included in a generalised estimating equations (GEE) logistic regression model using a compound symmetry covariance structure within centres. The GEE model accounts for correlation between patients who refer to the same centre. We performed separate analyses in three subgroups: (i) children tested because of symptoms suggestive of COVID-19, (ii) asymptomatic children tested because of contact with a case with a SARS-CoV-2-positive test and (iii) hospitalised children tested a $\mathrm{s}$ part of a hospital screening programme. The analyses of children tested because of symptoms suggestive of COVID19 were predefined as our primary analyses, while the analyses in the other two subgroups were considered secondary analyses. An exploratory subgroup analysis was performed on disease severity by age group and sex in patients with symptoms suggestive of COVID-19. We also performed secondary analyses to describe variation across centres in the rate of children with positive SARS-CoV-2 tests. The significance level was set at 0.05 (two-tailed test). Data were analysed with STATA 14 and SAS 9.4.

\section{Ethical statement}

The study was approved by the Institutional Review Board of the Institute for Maternal and Child Health IRCCS Burlo Garofolo, Trieste, Italy (reference number $01 / 202025.03 .2020$ ). Data were collected in an anonymous way, analysed and reported only in aggregate form. Given the purely descriptive and retrospective nature of the study, informed consent was waived. 
Clinical presentation of SARS-CoV-2-positive children, Italy, 23 February-24 May 2020 (n =159)

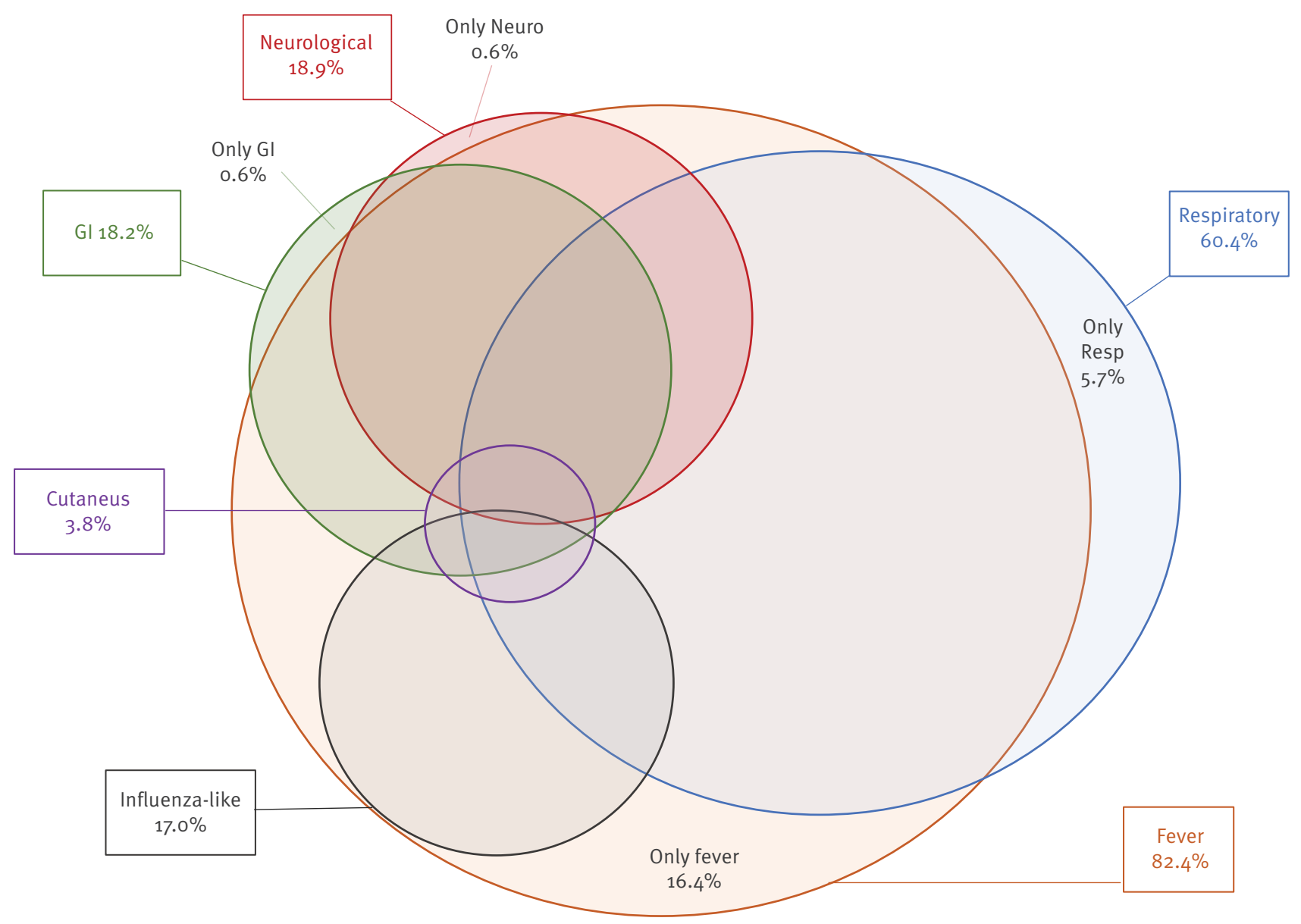

GI: gastrointestinal; SARS-CoV-2: severe acute respiratory syndrome coronavirus 2.

\section{Results}

During the study period, 2,494 children were tested for SARS-CoV-2 across 20 centres (Figure 1). Geographical case distribution is depicted in Supplementary Figure S1. In the total sample, $2,148(86.1 \%)$ children were tested because of symptoms suggestive of COVID-19, $52(2.1 \%)$ asymptomatic children were tested because of contact with a SARS-CoV-2-positive case and 294 $(11.8 \%)$ children were tested within hospital screening programmes. Among all the tested children, 190 (7.6\%) resulted positive. The percentage of positive cases was significantly higher in those tested because of a SARSCoV-2-positive contact (COVID-19-positive rate: $51.9 \%$ ) than in those tested because of symptoms (SARS-CoV2-positive rate: $7.4 \%$; $p<0.0001$ ) or in hospital screening programmes (SARS-CoV-2-positive rate: $2.1 \%$; $\mathrm{p}<0.0001$ ) (Figure 1).

The clinical presentations of the 159 SARS-CoV-2positive cases tested because of symptoms included, besides fever and/or respiratory signs or symptoms, gastrointestinal, neurological and dermatological manifestations and other unspecific influenza-like features (Figure 2). Specifically, 131 children (82.4\%) had fever, which presented as the only symptom in 26 (16.4\%), and $96(60.4 \%)$ had respiratory signs/symptoms, which presented alone in nine (5.7\%). Neurological symptoms such as convulsion, irritability, headache, anosmia/ageusia were observed in 30 (18.9\%), in one child as the only symptom. Unspecific general influenza-like symptoms -such as muscular-articular pains, nausea and poor appetite- were reported in 27 (17.0\%), always in combination with other clinical signs. Six children were tested because of cutaneous signs such as vasculitis and pseudo-chilblains on fingertips and toes, always in association with other symptoms of any type (fever, respiratory, neurological, unspecific influenzalike symptoms, or gastrointestinal symptoms ).

When comparing children based on the results of swab testing (Table 1), SARS-CoV-2-positive children were more often in the stratum of 10-18 years compared with the SARS-CoV-2-negative (54.1\% vs $26.0 \%$; $p<0.001$ ). No difference by sex was observed. A history of SARSCoV-2-positive contact was strongly associated with an increased risk of a positive swab (79.2\% vs $6.1 \%$; $\mathrm{p}<0.001)$. Similarly, having a relative with respiratory symptoms was strongly associated with SARS-CoV-2positive test results ( $72.3 \%$ vs $11.5 \%$; $p<0.001)$. Both positive and negative children had a non-negligible 
TABLE 1

Socio-demographic characteristics of children tested for SARS-CoV-2 because of symptoms suggestive of COVID-19, Italy, 23 February-24 May $2020(\mathrm{n}=2,148)$

\begin{tabular}{|c|c|c|c|c|c|}
\hline \multirow[t]{2}{*}{ Characteristics } & \multicolumn{2}{|c|}{$\begin{array}{l}\text { Positive swab } \\
\qquad n=159\end{array}$} & \multicolumn{2}{|c|}{$\begin{array}{l}\text { Negative swab } \\
\qquad n=1,989\end{array}$} & \multirow[t]{2}{*}{$p$ value } \\
\hline & $n$ & $\%$ & $\mathrm{n}$ & $\%$ & \\
\hline \multicolumn{6}{|l|}{ Age group } \\
\hline$<6$ months & 19 & 12.0 & 159 & 8.0 & 0.082 \\
\hline $6-<24$ months & 17 & 10.7 & 472 & $23 \cdot 7$ & $<0.001$ \\
\hline $2-9$ years & 37 & 23.3 & 836 & 42.0 & $<0.001$ \\
\hline $10-18$ years & 86 & 54.1 & 517 & 26.0 & $<0.001$ \\
\hline Missing & 0 & 0 & 5 & 0.3 & 1.000 \\
\hline \multicolumn{6}{|l|}{ Sex } \\
\hline Male & 77 & 48.4 & 1,108 & $55 \cdot 7$ & 0.076 \\
\hline Female & 82 & 51.6 & 880 & 44.2 & 0.074 \\
\hline Missing & 0 & 0 & 1 & 0.1 & 1.000 \\
\hline Contact with COVID-19 case & 126 & 79.2 & 122 & 6.1 & $<0.001$ \\
\hline Relatives with respiratory symptoms & 115 & 72.3 & 229 & 11.5 & $<0.001$ \\
\hline Any comorbidity & 28 & 17.6 & 327 & 16.4 & 0.702 \\
\hline \multicolumn{6}{|l|}{ Type of comorbidity } \\
\hline Malformation, disabilities, neuromuscular diseases & 5 & 3.1 & 81 & 4.1 & 0.566 \\
\hline Cardiac diseases & 9 & 5.7 & 42 & 2.1 & 0.005 \\
\hline Asthma & 6 & 3.8 & 60 & 3.0 & 0.593 \\
\hline Other respiratory diseases/conditions & 0 & 0 & 17 & 0.9 & 0.631 \\
\hline Primary immunodeficiencies & 1 & 0.6 & 12 & 0.6 & 1.000 \\
\hline Secondary immunodeficiencies & 1 & 0.6 & 41 & 2.1 & 0.365 \\
\hline Obesity & 1 & 0.6 & 12 & 0.6 & 1.000 \\
\hline Diabetes & 1 & 0.6 & 2 & 0.1 & 0.206 \\
\hline Psychiatric disorders & 1 & 0.6 & 21 & 1.1 & 1.000 \\
\hline Other & 9 & $5 \cdot 7$ & 97 & 4.9 & 0.659 \\
\hline
\end{tabular}

COVID-19: coronavirus disease; SARS-CoV-2: severe acute respiratory syndrome coronavirus 2.

rate of comorbidities ( $17.6 \%$ vs $16.4 \% ; p=0.7$ ), with cardiac diseases being slightly more frequent in the group testing positive for SARS-CoV-2 (5.7\% vs $2.1 \%$; $p=0.005)$.

When compared for disease severity at presentation (Table 2), there were no significant differences between children who were SARS-CoV-2-positive and those who were negative. Most cases had a mild presentation $(78 \%$ and $70.8 \%$, respectively; $p=0.053)$. Severe (3.1\% vs $6.7 \% ; p=0.091)$ or critical presentation $(1.3 \%$ vs $1.0 \% ; p=0.665$ ) had the same frequency in SARSCoV-2-positive and those who were negative.

Fever was highly prevalent in both groups, significantly more in SARS-CoV-2-positive children (82.4\% vs $68.1 \%$, p $<0.001)$. Respiratory symptoms were highly prevalent in both groups $(60.4 \%$ vs $66.6 \% ; p=0.110)$ with some differences: dry cough was more frequent in the group of SARS-CoV-2-positive individuals $(32.1 \%$ vs $22.7 \%$; $p=0.007)$, whereas sore throat and pharyngitis, were less frequent $(22.6 \%$ vs $44.3 \%$; $p<0.001$ and $1.3 \%$ vs $5.3 \% ; p=0.024$ respectively). Respiratory distress was less frequent in the group testing positive for SARS-CoV-2 than in the group testing negative, although the difference was not statistically significant $(7.5 \%$ vs $12.8 \% ; p=0.052)$. Gastrointestinal symptoms $(18.2 \%$ vs $28.9 \% ; p=0.004)$ and other symptoms $(14.5 \%$ vs $26.6 \% ; p=0.001)$ were significantly less frequent in the SARS-CoV-2-positive group, while the opposite was true of neurological symptoms $(18.9 \%$ vs $8.8 \% ; p<0.001)$ and muscle or joint pains ( $11.3 \%$ vs $3.6 \% ; p<0.001)$.

Vital parameters as well as oxygen saturation levels and lung auscultation were not significantly different between the two groups. Lymphocytopenia was significantly more frequent in the SARS-CoV-2-positive group (34.0\% vs $13.5 \%$; $p<0.001$ ), while elevated C-reactive protein was more frequent in the SARS-CoV-2-negative group ( $58.0 \%$ vs $77.5 \% ; p=0.002)$. Findings at chestX-ray, lung ultrasound and lung computed tomography scan were not significantly different between the two groups, with equal prevalence of ground glass opacities in SARS-CoV-2-positive and those who were negative (respectively $25.9 \%$ vs $22.7 \%$; $=0.7$ and $40.0 \%$ vs $51.7 \% ; p=0.67)$. 


\section{TABLE 2A}

Clinical presentation and outcomes of children tested for SARS-CoV-2 because of symptoms suggestive of COVID-19, Italy, 23 February-24 May $2020(\mathrm{n}=2,148)$

\begin{tabular}{|c|c|c|c|c|c|}
\hline \multirow[t]{2}{*}{ Clinical presentation and outcomes } & \multicolumn{2}{|c|}{$\begin{array}{l}\text { Positive swab } \\
\qquad n=159\end{array}$} & \multicolumn{2}{|c|}{$\begin{array}{l}\text { Negative swab } \\
\qquad n=1,989\end{array}$} & \multirow[t]{2}{*}{$\mathrm{p}$ value } \\
\hline & $\mathrm{n}$ & $\%$ & $\mathrm{n}$ & $\%$ & \\
\hline
\end{tabular}

\begin{tabular}{|c|c|c|c|c|c|}
\hline Asymptomatic & 8 & 5.0 & 125 & 6.3 & 0.528 \\
\hline Mild & 124 & 78.0 & 1,408 & 70.8 & 0.053 \\
\hline Moderate & 20 & 12.6 & 304 & 15.3 & 0.359 \\
\hline Severe & 5 & 3.1 & 133 & 6.7 & 0.091 \\
\hline Critical & 2 & 1.3 & 19 & 1.0 & 0.665 \\
\hline \multicolumn{6}{|l|}{ Symptoms and signs at presentation } \\
\hline Fever & 131 & 82.4 & 1,355 & 68.1 & $<0.001$ \\
\hline Respiratory symptoms, any & 96 & 60.4 & 1,325 & 66.6 & 0.110 \\
\hline Respiratory distress & 12 & 7.5 & 255 & 12.8 & 0.052 \\
\hline Rhinorrhoea & 32 & 20.1 & 372 & 18.7 & 0.659 \\
\hline Dry cough & 51 & 32.1 & 452 & 22.7 & 0.007 \\
\hline Productive cough & 7 & 4.4 & 185 & 9.3 & 0.037 \\
\hline Sore throat & 36 & 22.6 & 881 & $44 \cdot 3$ & $<0.001$ \\
\hline Pharyngitis & 2 & 1.3 & 106 & 5.3 & 0.024 \\
\hline Conjunctivitis & 8 & 5.0 & 60 & 3.0 & 0.163 \\
\hline Apnoea & 0 & 0 & 4 & 0.2 & 1.000 \\
\hline Thoracic pain & 6 & 3.8 & 44 & 2.2 & 0.209 \\
\hline Gastrointestinal symptoms, any & 29 & 18.2 & 574 & 28.9 & 0.004 \\
\hline Vomiting & 16 & 10.1 & 365 & 18.3 & 0.009 \\
\hline Diarrhoea & 18 & 11.3 & 293 & 14.7 & 0.240 \\
\hline Neurological symptoms, any & 30 & 18.9 & 175 & 8.8 & $<0.001$ \\
\hline Asthenia & 10 & 6.3 & 38 & 1.9 & $<0.001$ \\
\hline Headache & 13 & 8.2 & 79 & 4.0 & 0.012 \\
\hline Anosmia/ageusia & 13 & 8.2 & 10 & 0.5 & $<0.001$ \\
\hline Convulsion & 2 & 1.3 & 49 & 2.5 & 0.583 \\
\hline Hyperactivity & 1 & 0.6 & 12 & 0.6 & 1.000 \\
\hline Cutaneous presentations, any & 6 & 3.8 & 159 & 8.0 & 0.054 \\
\hline Skin manifestations & 6 & 3.8 & 158 & 7.9 & 0.057 \\
\hline Vasculitis & 0 & 0 & 11 & 0.6 & 1.000 \\
\hline Unspecific influenza-like presentations, any & 27 & 17.0 & 303 & 15.2 & 0.557 \\
\hline Muscle or joint pains & 18 & 11.3 & 71 & 3.6 & $<0.001$ \\
\hline Nausea & 0 & 0 & 13 & 0.7 & 0.616 \\
\hline Inappetence & 15 & 9.4 & 237 & 11.9 & 0.349 \\
\hline Lymphadenitis & 8 & 5.0 & 158 & 7.9 & 0.186 \\
\hline Other symptoms, any & 23 & 14.5 & 528 & 26.6 & 0.001 \\
\hline Abdominal pains & 11 & 6.9 & 269 & 13.5 & 0.017 \\
\hline Oral manifestations (gingivostomatitis, aphthae) & 2 & 1.3 & 54 & 2.7 & 0.433 \\
\hline Dental problems & 1 & 0.6 & 6 & 0.3 & 0.417 \\
\hline Urogenital disorders & o & 0 & 10 & 0.5 & 1.000 \\
\hline Ear problems & 0 & 0 & 32 & 1.6 & 0.166 \\
\hline Others & 3 & 1.9 & 41 & 2.1 & 1.000 \\
\hline \multicolumn{6}{|l|}{ Vital parameters at presentation } \\
\hline Tachycardia & $12 / 61$ & 19.7 & $294 / 1,489$ & 19.7 & 0.989 \\
\hline Tachypnoea & $4 / 34$ & 11.8 & $187 / 827$ & 22.6 & 0.204 \\
\hline
\end{tabular}




\section{TABLE 2B}

Clinical presentation and outcomes of children tested for SARS-CoV-2 because of symptoms suggestive of COVID-19, Italy, 23 February-24 May $2020(\mathrm{n}=2,148)$

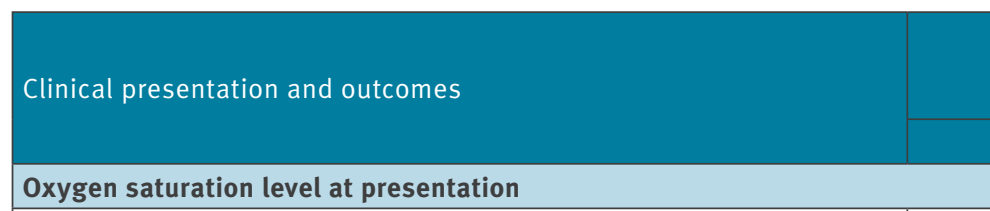

Positive swab

$n=159$

n
Negative swab

$n=1,989$

$\mathrm{n}$

Oxygen saturation level at presentation

$91-92 \%$

$\leq 90 \%$

\begin{tabular}{l|l|l|l|l}
$2 / 66$ & 3.0 & $15 / 1,575$ & 1.0 & 0.147 \\
\hline $1 / 66$ & 1.5 & $21 / 1,575$ & 1.3 & 0.597
\end{tabular}

\section{Clinical examination at presentation}

Lung auscultation

Negative

Crackles

Wheezing

Absent breath sounds

\begin{tabular}{|l|l}
\hline $2 / 66$ \\
$1 / 66$
\end{tabular}

1.5

$21 / 1,575$

0.597

Laboratory testa

White blood cell count $<5.5(\times 109 / \mathrm{L})$

Lymphocyte count $<1.2(\times 109 / \mathrm{L})$

Neutrophil<1.50 (× 109/L)

C-reactive protein $>1 \mathrm{gr} / \mathrm{dL}$

Erythrocyte sedimentation rate $>20 \mathrm{~mm} / \mathrm{h}$

Aspartate aminotransferase $>50(\mathrm{U} / \mathrm{L})$

Alanine aminotransferase $>45(\mathrm{U} / \mathrm{L})$

D dimer $>0.5(\mu \mathrm{g} / \mathrm{mL})$

\section{Chest X-ray}

Negative

Ground glass opacities

Focal consolidation

Other description

Lung ultrasound

Negative

B-lines in various pattern

Focal consolidation

Other description

Lung CT scan

Negative

Ground glass opacities

Focal consolidation

Other description

\section{Hospitalised}

Respiratory support ${ }^{a}$

Oxygen

High flow oxygen

Non-invasive ventilation

Mechanical ventilation

Cases in ICU

\begin{tabular}{|c|c|c|c|c|}
\hline $69 / 86$ & 80.2 & $1,486 / 1,826$ & 81.3 & 0.810 \\
\hline $4 / 86$ & 4.7 & $186 / 1,826$ & 10.2 & 0.099 \\
\hline $3 / 86$ & 3.5 & $120 / 1,826$ & 5.6 & 0.366 \\
\hline $4 / 86$ & 4.7 & $111 / 1,826$ & 6.1 & 0.816 \\
\hline
\end{tabular}

\section{Outcome}

Cured

Referred

Died

\begin{tabular}{|c|c|c|c|c|}
\hline $17 / 50$ & 34.0 & $109 / 809$ & 13.5 & $<0.001$ \\
\hline $8 / 41$ & $19 \cdot 5$ & $75 / 559$ & 13.4 & 0.275 \\
\hline $6 / 47$ & 12.8 & $50 / 743$ & 6.7 & 0.118 \\
\hline $29 / 50$ & 58.0 & $589 / 760$ & 77.5 & 0.002 \\
\hline $2 / 4$ & 50.0 & $34 / 64$ & 53.1 & 1.000 \\
\hline $7 / 35$ & 20.0 & $56 / 434$ & 12.9 & 0.234 \\
\hline $4 / 46$ & 8.7 & $74 / 692$ & 10.7 & 0.808 \\
\hline $2 / 4$ & 50.0 & $24 / 46$ & 52.2 & 1.000 \\
\hline 27 & 17.0 & 313 & $15 \cdot 7$ & 0.679 \\
\hline $8 / 27$ & 29.6 & $106 / 313$ & 33.9 & 0.655 \\
\hline $7 / 27$ & 25.9 & $71 / 313$ & 22.7 & 0.701 \\
\hline $3 / 27$ & 11.1 & $77 / 313$ & 24.6 & 0.155 \\
\hline $9 / 27$ & 33.3 & $59 / 313$ & 18.8 & 0.071 \\
\hline 5 & 3.1 & 58 & 2.9 & 0.806 \\
\hline $1 / 5$ & 20.0 & $18 / 58$ & 31.0 & 1.000 \\
\hline $2 / 5$ & 40.0 & $30 / 58$ & 51.7 & 0.672 \\
\hline 0 & 0 & $5 / 58$ & 8.6 & 1.000 \\
\hline $1 / 5$ & 20.0 & $1 / 58$ & 1.7 & 0.154 \\
\hline 5 & 3.1 & 13 & 0.7 & 0.008 \\
\hline $0 / 5$ & 0 & $2 / 13$ & $15 \cdot 4$ & 1.000 \\
\hline $3 / 5$ & 60.0 & $6 / 13$ & 46.2 & 1.000 \\
\hline $1 / 5$ & 20.0 & $3 / 13$ & 23.1 & 1.000 \\
\hline $0 / 5$ & 0 & $2 / 13$ & 15.4 & 1.000 \\
\hline 45 & 28.3 & 602 & 30.3 & 0.603 \\
\hline 4 & 2.5 & 73 & 3.7 & 0.656 \\
\hline $3 / 45$ & 6.7 & $54 / 602$ & 9.0 & 0.788 \\
\hline $2 / 45$ & $4 \cdot 4$ & $19 / 602$ & 3.2 & 0.651 \\
\hline $1 / 45$ & 2.2 & 4/602 & 0.7 & 0.303 \\
\hline $0 / 45$ & 0 & $11 / 602$ & 1.8 & 1.000 \\
\hline 2 & 1.3 & 11 & 0.6 & 0.250 \\
\hline 159 & 100 & 1,981 & 99.6 & 0.500 \\
\hline 0 & 0 & 7 & 0.4 & 0.460 \\
\hline 0 & 0 & 1 & 0.1 & 1.000 \\
\hline
\end{tabular}

COVID-19: coronavirus disease; ICU: intensive care unit; SARS-CoV-2: severe acute respiratory syndrome coronavirus 2.

available in a subsample of cases. 
TABLE 3

Multivariate analysis of characteristics and risk indicators for SARS-CoV-2 in children, Italy, 23 February-24 May $2020(\mathrm{n}=2,148)$

\begin{tabular}{|c|c|c|}
\hline Characteristics & $\begin{array}{c}\text { Adjusted OR }(95 \% \\
\mathrm{Cl})\end{array}$ & $p$ value \\
\hline \multicolumn{3}{|l|}{ Age group } \\
\hline$<6$ months & $1.12(0.60-2.11)$ & 0.725 \\
\hline $6-<24$ months & $0.43(0.15-1.20)$ & 0.107 \\
\hline $2-9$ years & $0.33(0.22-0.50)$ & $<0.0001$ \\
\hline $10-18$ years & \multicolumn{2}{|l|}{ Reference } \\
\hline \multicolumn{3}{|l|}{ Risk indicator } \\
\hline $\begin{array}{l}\text { Contact with SARS-CoV-2- } \\
\text { positive case }\end{array}$ & $39.83(17.52-90.55)$ & $<0.0001$ \\
\hline Cardiac disease & $3.10(1.19-5.02)$ & $<0.0001$ \\
\hline Fever & $3.05(1.67-5.58)$ & 0.0003 \\
\hline Dry cough & $1.31(0.87-2.01)$ & 0.199 \\
\hline Productive cough & $0.53(0.18-1.53)$ & 0.242 \\
\hline Sore throat & $0.54(0.29-1.03)$ & 0.063 \\
\hline Pharyngitis & $0.41(0.09-1.86)$ & 0.246 \\
\hline Vomiting & $1.01(0.68-1.50)$ & 0.963 \\
\hline Asthenia & $0.94(0.31-2.84)$ & 0.911 \\
\hline Headache & $0.98(0.52-1.87)$ & 0.956 \\
\hline Anosmia/ageusia & $4.08(1.69-9.84)$ & 0.002 \\
\hline Muscle or joint pain & $1.76(0.86-3.63)$ & 0.124 \\
\hline Abdominal pains & $1.05(0.57-1.94)$ & 0.882 \\
\hline
\end{tabular}

$\mathrm{Cl}$ : confidence interval; OR: odds ratio; SARS-CoV-2: severe acute respiratory syndrome coronavirus 2 .

The frequencies of hospitalised cases $(28.3 \%$ vs $30.3 \%$; $\mathrm{p}=0.60$ ) and those admitted to an intensive care unit (ICU) $(1.3 \%$ vs $0.6 \% ; p=0.25)$ were not significantly different between the SARS-CoV-2-positive and -negative children. Need and type of respiratory support were also not significantly different. Final outcomes did not differ between groups, although one death occurred in the SARS-CoV-2-negative group.

\section{Multivariate analysis}

In multivariate analysis, factors significantly associated with testing positive for SARS-CoV-2 were: contact with COVID-19-positive patient (odds ratio (OR): 39.83; 95\% confidence interval (Cl): 17.52-90.55; $\mathrm{p}<0.0001)$, pre-existing cardiac disease (OR: 3.10; $95 \% \mathrm{Cl}: 1.19-$ 5.02; $p<0.0001$ ), fever (OR: 3.05\%; 95\% Cl: 1.67-5.58; $\mathrm{p}=0.0003$ ) and anosmia/ageusia (OR: $4.08 ; 95 \% \mathrm{Cl}$ : 1.69-9.84; $p=0.002$ ) (Table 3). Age between 2 and 9 years was negatively associated with testing positive for COVID-19, when taking the group of $10-18$ years as reference (OR: $0.33 ; 95 \% \mathrm{Cl}: 0.22-0.50 ; \mathrm{p}<0.0001)$.

\section{Secondary analyses}

Additional details on the 190 children positive for SARS-CoV-2 are reported in Supplementary Table S3. Overall, 139 (73.1\%) children were cared for at home. The remaining were hospitalised in two types of wards: paediatric wards $(n=25 ; 55.6 \%)$ and general COVID19 wards $(n=24 ; 53.3 \%)$. Cases treated with home care were either asymptomatic or had a mild or moderate presentation. The children received different types of treatments; antibiotics, steroids and hydroxychloroquine were more frequently prescribed among hospitalised children (respectively $35.6 \%$ vs $10.5 \%$; p $<0.001,8.9 \%$ vs $0.0 \% ; p=0.006$ and $8.9 \%$ vs $0.0 \%$; $\mathrm{p}=0.006$ ), while antipyretics/analgesic were much more frequently used in home care management $(2.2 \%$ vs $51.8 \%$; $p$ (0.001).

Sociodemographic data, clinical characteristics and outcomes of children tested because of a COVID-19positive contact and of those tested through hospital screening are reported in Supplementary Table S4. No significant difference was observed for any variable between the SARS-CoV-2-positive individuals and the negatives in these two groups. None of the children positive for SARS-CoV-2 in these groups had respiratory distress, none required respiratory support, none were admitted to ICU and all recovered.

No difference in disease severity was observed by age and sex, in SARS-CoV-2-positive children $(n=159)$ (Table 4).

\section{Discussion}

This study adds to previous knowledge a description of characteristics and risk factors for SARS-CoV-2 among children from the early stages of the COVID-19 pandemic in Europe. Notably, the clinical presentation of children with SARS-CoV-2 includes different possible scenarios. Besides the typical clinical picture with fever and respiratory signs or symptoms, this study suggested that COVID-19 in children may have neurological, gastrointestinal, or cutaneous presentations, either in combination with other presentations or alone. These results are in line with reports from rheumatologists and dermatologists $[27,28]$, gastroenterologists [29], neurologists and psychiatrists [30,31]. Although the case definition of 'suspected case of SARS-CoV-2 infection' was updated by the WHO in December 2020 [32], it does not yet include all possible clinical presentations of COVID-19, as highlighted by this study and other evidence in the literature [27-31]. Findings from COVID-19 screening among categories of people at risk, such as health workers, indicate that the current guidelines [26] for testing may risk missing many cases [33]. Furthermore, it is important to acknowledge that, because the recommendations on SARS-CoV-2 case identification at the time of this study indicated testing only for cases with either fever or respiratory signs $[26,34]$, the real prevalence of other presentations (e.g. gastrointestinal, neurological and cutaneous) may have gone underestimated in this study, as well as in other studies. Guidelines for SARS-CoV-2 testing should be updated based on the evidence on clinical presentation of the disease in children and adults.

Our findings suggest that, in contrast with what has been observed in adults $[18,19]$, there are very few features in children which help differentiate those 
TABLE 4

Disease severity by sex and age in SARS-CoV-2-positive children with symptoms suggestive of COVID-19, Italy, 23 February-24 May $2020(\mathrm{n}=159)$

\begin{tabular}{|c|c|c|c|c|c|c|c|c|}
\hline \multirow{3}{*}{ Disease severity } & \multicolumn{8}{|c|}{ Sex } \\
\hline & \multicolumn{4}{|c|}{ Male $n=77$} & \multicolumn{4}{|c|}{ Female $n=82$} \\
\hline & \multicolumn{2}{|c|}{$\mathrm{n}$} & \multicolumn{2}{|c|}{$\%$} & \multicolumn{2}{|c|}{$n$} & \multicolumn{2}{|c|}{$\%$} \\
\hline Asymptomatic & \multicolumn{2}{|c|}{4} & \multicolumn{2}{|c|}{5.2} & \multicolumn{2}{|c|}{4} & \multicolumn{2}{|c|}{4.9} \\
\hline Mild & \multicolumn{2}{|c|}{56} & \multicolumn{2}{|c|}{72.7} & \multicolumn{2}{|c|}{68} & \multicolumn{2}{|c|}{82.9} \\
\hline Moderate & \multicolumn{2}{|c|}{13} & \multicolumn{2}{|c|}{16.9} & \multicolumn{2}{|c|}{7} & \multicolumn{2}{|c|}{8.5} \\
\hline Severe & \multicolumn{2}{|c|}{3} & \multicolumn{2}{|c|}{3.9} & \multicolumn{2}{|c|}{2} & \multicolumn{2}{|c|}{2.4} \\
\hline Critical & \multicolumn{2}{|c|}{1} & \multicolumn{2}{|c|}{1.3} & \multicolumn{2}{|r|}{1} & \multicolumn{2}{|c|}{1.2} \\
\hline \multirow{3}{*}{ Disease severity } & \multicolumn{8}{|c|}{ Age } \\
\hline & \multicolumn{2}{|c|}{$\begin{array}{c}\text { < } 6 \text { months } \\
n=19\end{array}$} & \multicolumn{2}{|c|}{$\begin{array}{c}6-<24 \text { months } \\
n=17\end{array}$} & \multicolumn{2}{|c|}{$\begin{array}{c}\text { 2-9 years } \\
n=37\end{array}$} & \multicolumn{2}{|c|}{$\begin{array}{c}10-18 \text { years } \\
n=86\end{array}$} \\
\hline & $\mathbf{n}$ & $\%$ & $\mathbf{n}$ & $\%$ & $\mathbf{n}$ & $\%$ & $n$ & $\%$ \\
\hline Asymptomatic & 3 & 15.8 & 1 & $5 \cdot 9$ & 2 & 5.4 & 2 & 2.3 \\
\hline Mild & 11 & 57.9 & 14 & 82.4 & 32 & 86.5 & 67 & 77.9 \\
\hline Moderate & 3 & 15.8 & 1 & $5 \cdot 9$ & 1 & 2.7 & 15 & $17 \cdot 4$ \\
\hline Severe & 1 & $5 \cdot 3$ & 1 & $5 \cdot 9$ & 1 & 2.7 & 2 & 2.3 \\
\hline Critical & 1 & 5.3 & 0 & 0 & 1 & 2.7 & 0 & 0 \\
\hline
\end{tabular}

COVID-19: coronavirus disease; ICU: intensive care unit; SARS-CoV-2: severe acute respiratory syndrome coronavirus 2.

There was no significant difference $(p<0.05)$ by age and sex.

affected by SARS-CoV-2 from those with other conditions. Specifically, some of the features identified so far in the few existing studies as predicting factors for COVID-19 in adults, such as obesity, leukopenia, lymphocytopenia, ground glass opacity at X-ray and having both lungs affected [19], were not confirmed in children. This seems plausible, considering the generally mild presentation of SARS-CoV-2 in the paediatric age range and the large number of other viruses which can affect children and result in clinical pictures very similar to COVID-19.

Our findings indicate that a diagnosis of SARS-CoV-2 may be much more probable in those who had contact with a person testing positive for SARS-CoV-2 (OR: 39.83; $95 \% \mathrm{Cl}: 17.52-90.55)$ or in children with fever (OR: 3.05 ; $95 \% \mathrm{Cl}: 1.67-5.58)$ or anosmia/ageusia (OR: 4.08; $95 \% \mathrm{Cl} 1.69-9.84 ; \mathrm{p}=0.002)$. These results are in line with studies in adults $[19,30]$ and underscore the importance of testing all cases with exposure history and increased body temperature, as well as those with peculiar neurological signs.

Our findings related to young age as a protective factor (with children in the age range 2-9 years being at lower risk of COVID-19 compared with the reference group of 10-18-year-olds: OR: 0.33 ; $95 \% \mathrm{Cl}: 0.22-$ 0.50 ) and to presence of cardiac disease as a risk factor (OR: 3.10; 95\% Cl: 1.19-5.02) are novel and warrant further confirmation and identification of causal mechanisms. Interestingly, about one in six children accessing the health system with a presentation suggestive of COVID-19 had a comorbidity (355/2,148; $16.5 \%)$. Nevertheless, the only comorbidity associated with positive testing for SARS-CoV-2 was pre-existing cardiac disease. Interestingly, pre-existing chronic kidney disease was a significant predictive factor for COVID-19 diagnosis in one large study at the primary care level in England, not specific to children [18]. These results should be confirmed in larger studies in children. More studies should explore if other factors apparently important in adults [18] - such as ethnicity, living situation, deprivation, children with smoking parents or obesity - increase the risk of COVID-19 in children.

This study suggests that COVID-19 has been a mild disease in children in Italy: among the 190 children diagnosed with SARS-CoV-2 in our study, 12 (6.3\%) had respiratory distress, only four $(2.1 \%)$ required respiratory support, only two (1.1\%) were admitted to ICU and all of them recovered. These results are in line with surveillance data in Italy [35], and with previous reports on COVID-19 in children from different countries $[4-6,16,36,37]$. According to existing surveillance data from the United States (US) Centers for Disease Control and Prevention, the number of deaths among children under 15 years of age with COVID-19 in the United States was much lower than what was reported for children with seasonal influenzas in 2019/20 (17 reported deaths for COVID-19 compared with 182 influenza-associated paediatric deaths) $[38,39]$. In contrast, data from adults indicate that COVID-19 may be more severe than influenzas in this population [40].

The sample of children hospitalised in this study was small (51 cases) but not negligible when compared with national data at the time of the study: by 20 May 
2020, the Italian surveillance systems had reported 227,204 confirmed SARS-CoV-2 cases in Italy, but only 123 hospitalised cases among children (i.e. age below 18 years) [35]. Our sample of 51 children hospitalised with COVID-19 thus accounts for $41.4 \%$ of the total paediatric cases reported by national surveillance [35]. Clearly, larger prevalence studies as well as prospective longitudinal studies are needed to better understand the risk associated with COVID-19 in selected subpopulations of children at risk. Despite current preliminary evidence suggesting that even in children with underlying conditions - such as inflammatory bowel diseases [41], cancer [42], dialysis [43] and renal diseases with steroid treatment [44] - the risk of severe COVID-19 disease may be limited, much more solid data are needed.

This study highlights several interesting epidemiological findings, reporting the number of children tested in several centres in the early phase of the pandemic and the rate of positivity. High heterogeneity across centres in the rate of positive SARS-CoV-2 testing is not surprising and may have multiple explanations. Firstly, the epidemiology of the disease differs across Italy, where regions in the north overall had a higher burden of cases compared with those in the south [45]. Secondly, case identification may have been affected by local protocols, testing capacities and different implementation of testing recommendations, both at study start and over time. The number of total swabs per population has been reported as highly variable across regions in Italy and not always directly proportional to the incidence of COVID-19 disease, with considerable variations over time [46]. The implementation of case finding and contact tracing has been described as highly heterogenous in other countries [47] and would warrant further investigation to better interpret epidemiological curves. Epidemiological data on COVID-19 may not reflect the real incidence of the disease in each setting, partly because of limitations in the currently available technology for COVID-19 diagnosis (i.e. high rates of false negatives with nasal or nasopharyngeal swabs [48]); it should, in general, be interpreted with extreme caution. Further studies should document knowledge, attitudes and practices of case finding and contact tracing. More accurate, acceptable and sustainable tools are also needed for COVID-19 diagnosis.

Limitations of this study include the retrospective nature of data, possible selection bias towards more symptomatic cases owing to the nature of the network, and the limitation in the technology currently available for COVID-19 diagnosis. Although the use of swabs is currently recommended as the gold standard for COVID-19 diagnosis, it has as major limitation of a high percentage of false negative cases [48]. Future studies, when better diagnostic tools will be available, should aim to confirm the observations of the present study. Strengths of this study include its pragmatic and descriptive nature, and the involvement of many paediatric centres in the national territory. More clinical and epidemiological studies are needed to further document the real incidence, presentation, risk factors and outcomes of children with COVID-19 infection in different paediatric subpopulations, to better characterise children at higher risk of the most severe forms of the disease.

Acknowledgements

We thank all staff of the research network that collaborated on this study.

Data sharing: De-identified individual participant data will be made available following completion of a data use agreement.

Members of the COVID-19 Italian Paediatric Study Network:

Daniele Perna MD, Giordano Palmas MD, Maria Moriondo PhD, Laura Baggio MD, Stefania lelo MD, Tommaso Bellini MD, Marta Vandone, Francesca Bonsignori, Rosa Castaldo, Elisabetta Grande, Giulia Guerrini, Alessandra Tabarrini MD, Giovanni Pieri MD, Ferrari Cristina MD, Frazzetto Fausto MD, Francesca Previati MD, Anna Pupo MD, Mauro Ramigni MD, Ester Chermaz MD, Rita de Rosa MD, Susanna Saletta MD, Cristina Milocco MD, Maria Teresa Calipa MD, Domenica Giglia MD, Paola Pisana MD, Patrizia Salierno MD, Patricia Petaros MD, Chiara Trevisiol MD, Paola Cogo MD.

\section{Conflict of interest}

None declared.

Authors' contributions

$M L$ conceptualised the study and wrote the first draft of the manuscript together with BA. ML finalised the manuscript. $I M$ and BA cleaned and analysed data. IS, ST, PB, DS, GV, JT, LB, EF, GP, RP, CG, SL, MC, FM, AM, PB, SM, FV, EV, MM, RDA, $S F, A G, A C, D D, P P, C P, I L, E M, F S, G T, A D S, A O, F C, R L, A T$, $M B, V M$ and EB collected the data.

All authors revised and approved the final manuscript.

\section{References}

1. World Health Organization (WHO). Coronavirus disease (COVID-2019) situation reports 11. Geneva: WHO; 31 January 2020. Available from: https://www.who.int/docs/defaultsource/coronaviruse/situation-reports/20200131-sitrep-11ncov.pdf?sfvrsn=de7cof $7 \_4$

2. Ministero della Salute. Covid-19 - Situazione in Italia. [COVID-19. Situation in Italy]. Rome: Ministero della Salute. [Accessed: 28 May 2020]. Italian. Available from: http://www.salute.gov.it/portale/nuovocoronavirus/ dettaglioContenutiNuovoCoronavirus.jsp?lingua =italiano $\& i d=5$ $351 \&$ area $=$ nuovoCoronavirus $\&$ menu $=$ vuoto

3. Ministero della Salute. COVID-19, i casi in Italia 24 maggio 2020. Aggiornamento nazionale 24 maggio 2020. [COVID-19, the cases in Italy on 24 May 2020. National update 24 May 2020]. Rome: Ministero della Salute. [Accessed: 29 Sep 2020]. Italian. Available from: http://www.salute.gov.it/portale/ nuovocoronavirus/dettaglioNotizieNuovoCoronavirus.jsp?lingu $a=i \operatorname{taliano\& menu}=$ notizie $\& p=$ dalministero $\& i d=4807$

4. Dong Y, Mo X, Hu Y, Qi X, Jiang F, Jiang Z, et al. Epidemiology of COVID-19 Among Children in China. Pediatrics. 2020.145(6):e20200702. https://doi.org/10.1542/ peds.2020-0702 
5. Parri N, Magistà AM, Marchetti F, Cantoni B, Arrighini A, Romanengo M, et al. Characteristic of COVID-19 infection in pediatric patients: early findings from two Italian Pediatric Research Networks. Eur J Pediatr. 2020;179(8):1315-23. https://doi.org/10.1007/s00431-020-03683-8 PMID: 32495147

6. Garazzino S, Montagnani C, Donà D, Meini A, Felici E, Vergine $\mathrm{G}$, et al. Multicentre Italian study of SARS-CoV-2 infection in children and adolescents, preliminary data as at 10 April 2020. Euro Surveill. 2020;25(18):2000600. https://doi. org/10.2807/1560-7917.ES.2020.25.18.2000600 PMID: 32400362

7. Tagarro A, Epalza C, Santos M, Sanz-Santaeufemia FJ, Otheo E, Moraleda C, et al. Screening and Severity of Coronavirus Disease 2019 (COVID-19) in Children in Madrid, Spain. JAMA Pediatr. 2020. https://doi.org/10.1001/ jamapediatrics.2020.1346 PMID: 32267485

8. Zachariah P, Johnson CL, Halabi KC, Ahn D, Sen Al, Fischer A, et al. Epidemiology, clinical features, and disease severity in patients with coronavirus disease 2019 (COVID-19) in a children's hospital in New York City, New York. JAMA Pediatr. 2020;174(10):e202430. https://doi.org/10.1001/ jamapediatrics.2020.2430 PMID: 32492092

9. Götzinger F, Santiago-García B, Noguera-Julián A, Lanaspa M, Lancella L, Calò Carducci FI, et al. COVID-19 in children and adolescents in Europe: a multinational, multicentre cohort study. Lancet Child Adolesc Health. 2020;4(9):653-61. https:// doi.org/10.1016/S2352-4642(20)30177-2 PMID: 32593339

10. Bialek S, Gierke R, Hughes M, McNamara LA, Pilishvili T, Skoff T, et al. Coronavirus Disease 2019 in Children - United States, February 12-April 2, 2020. MMWR Morb Mortal Wkly Rep. 2020;69(14):422-6. https://doi.org/10.15585/mmwr. mm6914e4 PMID: 32271728

11. Castagnoli R, Votto M, Licari A, Brambilla I, Bruno R, Perlini S, et al. Severe Acute Respiratory Syndrome Coronavirus 2 (SARS. CoV-2) Infection in Children and Adolescents: A Systematic Review. JAMA Pediatr. 2020;174(9):882-9. https://doi. org/10.1001/jamapediatrics.2020.1467 PMID: 32320004

12. Hoang A, Chorath K, Moreira A, Evans M, Burmeister-Morton $\mathrm{F}$, Burmeister $\mathrm{F}$, et al. COVID-19 in 7780 pediatric patients: A systematic review. EClinicalMedicine. 2020;24:100433. https://doi.org/10.1016/j.eclinm.2020.100433 PMID: 32766542

13. Zimmermann $P$, Curtis N. Coronavirus infections in children including COVID-19: an overview of the epidemiology, clinical features, diagnosis, treatment and prevention options in children. Pediatr Infect Dis J. 2020;39(5):355-68. https://doi. org/10.1097/INF.0000000000002660 PMID: 32310621

14. Mustafa NM, A Selim L. Characterisation of COVID-19 pandemic in paediatric age group: a systematic review and meta-analysis. J Clin Virol. 2020;128:104395. https://doi. org/10.1016/j.jcv.2020.104395 PMID: 32417675

15. Ludvigsson JF. Systematic review of COVID-19 in children shows milder cases and a better prognosis than adults. Acta Paediatr. 2020;109(6):1088-95. https://doi.org/10.1111/apa.15270 PMID: 32202343

16. Liguoro I, Pilotto C, Bonanni M, Ferrari ME, Pusiol A, Nocerino $A$, et al. SARS-COV-2 infection in children and newborns: a systematic review. Eur J Pediatr. 2020;179(7):1029-46. https:// doi.org/10.1007/s00431-020-03684-7 PMID: 32424745

17. Yoon S, Li H, Lee KH, Hong SH, Kim D, Im H, et al. Clinical characteristics of asymptomatic and symptomatic pediatric coronavirus disease 2019 (COVID-19): a systematic review. Medicina (Kaunas). 2020;56(9):E474. https://doi.org/10.3390/ medicina56090474 PMID: 32942705

18. de Lusignan S, Dorward J, Correa A, Jones N, Akinyemi O, Amirthalingam G, et al. Risk factors for SARS-CoV-2 among patients in the Oxford Royal College of General Practitioners Research and Surveillance Centre primary care network: a cross-sectional study. Lancet Infect Dis. 2020;20(9):103442. https://doi.org/10.1016/S1473-3099(20)30371-6 PMID: 32422204

19. Mao B, Liu Y, Chai YH, Jin XY, Lu HW, Yang JW, et al. Assessing risk factors for SARS-CoV-2 infection in patients presenting with symptoms in Shanghai, China: a multicentre, observational cohort study. Lancet Digit Health. 2020;2(6):e323-30. https://doi.org/10.1016/S25897500(20)30109-6 PMID: 32501440

20. Wynants L, Van Calster B, Collins GS, Riley RD, Heinze G, Schuit E, et al. Prediction models for diagnosis and prognosis of covid-19 infection: systematic review and critical appraisal. BMJ. 2020;369:m1328. https://doi.org/10.1136/bmj.m1328 PMID: 32265220

21. Ho FK, Celis-Morales CA, Gray SR, Vittal Katikireddi S, Niedzwiedz CL, Hastie C, et al. Modifiable and non-modifiable risk factors for COVID-19: results from UK Biobank; medRxiv 2020. https://doi.org/10.1101/2020.04.28.20083295
22. Peng D, Zhang J, Xu Y, Liu Z, Wu P. The role of procalcitonin in early differential diagnosis of suspected children with COVID-19; medRxiv 2020. https://doi.org/10.1101/2020.04.07 .20057315

23. Alizadehsani R, Alizadeh Sani Z, Behjati M, Roshanzamir Z, Hussain S, Abedini N, et al. Risk factors prediction, clinical outcomes, and mortality in COVID-19 patients. J Med Virol. 2021;93(4):2307-20. https://doi.org/10.1002/jmv.26699 PMID: 33247599

24. Hobbs CV, Martin LM, Kim SS, Kirmse BM, Haynie L, McGraw S, et al. Factors associated with positive SARS-CoV-2 test results in outpatient health facilities and emergency departments among children and adolescents aged $<18$ years - Mississippi, September-November 2020. MMWR Morb Mortal Wkly Rep. 2020;69(50):1925-9. https://doi.org/10.15585/mmwr. mm6950e3 PMID: 33332298

25. von Elm E, Altman DG, Egger M, Pocock SJ, Gøtzsche PC, Vandenbroucke JP, et al. The Strengthening the Reporting of Observational Studies in Epidemiology (STROBE) statement: guidelines for reporting observational studies. Lancet. 2007;370(9596):1453-7. https://doi.org/10.1016/S01406736(07)61602-X PMID: 18064739

26. Ministero della Salute. COVID-19. Aggiornamentodella definizione di caso. [COVID-19. Case definition update]. Rome: Ministero della Salute; Mar 2020. Italian. Available from: http://www.trovanorme.salute.gov.it/norme/renderNormsanPd $\mathrm{f}$ ?anno $=2020 \&$ codLeg $=73669$ \& parte $=1 \% 20 \&$ serie $=$ null

27. Verdoni L, Mazza A, Gervasoni A, Martelli L, Ruggeri M, Ciuffreda M, et al. An outbreak of severe Kawasaki-like disease at the Italian epicentre of the SARS-CoV-2 epidemic: an observational cohort study. Lancet. 2020;395(10239):17718. https://doi.org/10.1016/S0140-6736(20)31103-X PMID: 32410760

28. Recalcati S. Cutaneous manifestations in COVID-19: a first perspective. J Eur Acad Dermatol Venereol. 2020;34(5):e212-3. https://doi.org/10.1111/jdv.16387 PMID: 32215952

29. Tullie L, Ford K, Bisharat M, Watson T, Thakkar H, Mullassery D, et al. Gastrointestinal features in children with COVID-19: an observation of varied presentation in eight children. Lancet Child Adolesc Health. 2020;4(7):e19-20. https://doi. org/10.1016/S2352-4642(20)30165-6 PMID: 32442420

30. Whittaker A, Anson M, Harky A. Neurological Manifestations of COVID-19: A systematic review and current update. Acta Neurol Scand. 2020;142(1):14-22. https://doi.org/10.1111/ane.13266 PMID: 32412088

31. Rogers JP, Chesney E, Oliver D, Pollak TA, McGuire P, FusarPoli $P$, et al. Psychiatric and neuropsychiatric presentations associated with severe coronavirus infections: a systematic review and meta-analysis with comparison to the COVID-19 pandemic. Lancet Psychiatry. 2020;7(7):611-27. https://doi. org/10.1016/S2215-0366(20)30203-0 PMID: 32437679

32. World Health Organization (WHO). WHO COVID-19: case definitions: updated in public health surveillance for COVID-19, published 16 December 2020. Geneva: WHO; 2020. License: CC BY-NC-SA 3.0 IGO. Available from: https://apps.who.int/iris/ handle/10665/337834

33. Chow EJ, Schwartz NG, Tobolowsky FA, Zacks RLT, HuntingtonFrazier M, Reddy SC, et al. Symptom Screening at Illness Onset of Health Care Personnel With SARS-CoV-2 Infection in King County, Washington. JAMA. 2020;323(20):2087-9. https://doi. org/10.1001/jama.2020.6637 PMID: 32301962

34. World Health Organization (WHO). Global surveillance for COVID-19 caused by human infection with COVID-19 virus. Interim guidance, 20 March 2020. License: CC BY-NC-SA 3.0 IGO. Geneva: WHO; 2020. Available from: https://apps.who. int/iris/handle/10665/331506

35. Istituto superiore di Sanità (ISS). Epidemia COVID-19. Aggiornamento nazionale 20 maggio 2020. [COVID-19 epidemic. National update 20 May 2020]. Rome: ISS; 2020. Italian. Available from: https://www.epicentro.iss.it/ coronavirus/bollettino/Bollettino-sorveglianza-integrataCOVID-19_20-maggio-2020.pdf

36. Wu Z, McGoogan JM. Characteristics of and important lessons from the coronavirus disease 2019 (COVID-19) outbreak in China: summary of a report of 72314 cases from the Chinese Center for Disease Control and Prevention. JAMA. 2020;323(13):1239-42. https://doi.org/10.1001/ jama.2020.2648 PMID: 32091533

37. Shekerdemian LS, Mahmood NR, Wolfe KK, Riggs BJ, Ross CE, McKiernan CA, et al. Characteristics and outcomes of children with coronavirus disease 2019 (COVID-19) infection admitted to US and Canadian pediatric intensive care units. JAMA Pediatr. 2020;174(9):868-73. https://doi.org/10.1001/ jamapediatrics.2020.1948 PMID: 32392288

38. Centers for Disease Control and Prevention (CDC). Weekly updates by select demographic and geographic 
characteristics. Provisional death counts for coronavirus disease 2019 (COVID-19). Atlanta: CDC. [Accessed: 10 Jun 2020]. Available from: https://www.cdc.gov/nchs/nvss/vsrr/ covid_weekly/index.htm\#AgeAndSex

39. Centers for Disease Control and Prevention (CDC). Weekly U.S. influenza surveillance report. Atlanta: CDC. [Accessed: 10 Jun 2020]. Available from: https://www.cdc.gov/flu/weekly/\#S3

40. Burn E, You SC, Sena AG, Kostka K, Abedtash H, Abrahão MTF, et al. An international characterisation of patients hospitalised with COVID-19 and a comparison with those previously hospitalised with influenza; medRxiv. 2020. https://doi.org/ http://dx.doi.org/10.1101/2020.04.22.20074336

41. Turner D, Huang Y, Martín-de-Carpi J, Aloi M, Focht G, Kang B, et al. Corona virus disease 2019 and paediatric inflammatory bowel diseases: global experience and provisional guidance (march 2020) from the paediatric IBD Porto Group of European Society of Paediatric Gastroenterology, Hepatology, and Nutrition. J Pediatr Gastroenterol Nutr. 2020;70(6):727-33. https://doi.org/10.1097/MPG.0000000000002729 PMID: 32443020

42. Boulad F, Kamboj M, Bouvier N, Mauguen A, Kung AL. COVID-19 in children with cancer in New York City. JAMA Oncol. 2020;6(9):1459-60. https://doi.org/10.1001/ jamaoncol.2020.2028 PMID: 32401276

43. Hains DS, Schwaderer AL, Carroll AE, Starr MC, Wilson $A C$, Amanat F, et al. Asymptomatic seroconversion of immunoglobulins to SARS-CoV-2 in a pediatric dialysis unit. JAMA. 2020;323(23):2424-5. https://doi.org/10.1001/ jama.2020.8438 PMID: 32407440

44. Marlais M, Wlodkowski T, Vivarelli M, Pape L, Tönshoff B, Schaefer F, et al. The severity of COVID-19 in children on immunosuppressive medication. Lancet Child Adolesc Health. 2020;4(7):e17-8. https://doi.org/10.1016/S23524642(20)30145-0 PMID: 32411815

45. Istituto Superiore di Sanità (ISS). Epidemia COVID-19. Aggiornamento nazionale (appendice): 20 maggio 2020. [COVID-19 epidemic. National update (appendix): 20 May 2020]. Rome: ISS; May 2020. Italian. Available from: https:// www.epicentro.iss.it/coronavirus/bollettino/Bolletinosorveglianza-integrata-COVID-19_20-maggio-2020_appendix. pdf

46. GIMBE. Coronavirus: la giungla dei tamponi In alcune regioni test con il contagocce per paura di nuovi lockdown? [Coronavirus: the jungle of swabs. In some regions very few tests performed for fear of new lockdowns?]. Bologna: Fondazione GIMBE; 7 May 2020. Italian. Available from: https://www.gimbe.org/pagine/341/it/ comunicati-stampa?pagina $=19$

47. Godlee Fiona. Covid-19: Testing testing. BMJ. 2020;369:m1918.

48. Wang W, Xu Y, Gao R, Lu R, Han K, Wu G, et al. Detection of SARS-CoV-2 in different types of clinical specimens. JAMA. 2020;323(18):1843-4. https://doi.org/10.1001/jama.2020.3786 PMID: 32159775

\section{License, supplementary material and copyright}

This is an open-access article distributed under the terms of the Creative Commons Attribution (CC BY 4.0) Licence. You may share and adapt the material, but must give appropriate credit to the source, provide a link to the licence and indicate if changes were made.

Any supplementary material referenced in the article can be found in the online version.

This article is copyright of the authors or their affiliated institutions, 2021. 